\title{
Dimensional change measurements of conventional and flowable composite resins using a laser displacement sensor
}

\author{
Taira MIYASAKA and Hiroyuki OKAMURA \\ Department of Dental Materials Science, School of Life Dentistry at Tokyo, The Nippon Dental University, 1-9-20 Fujimi, Chiyoda-ku, Tokyo \\ 102-8159, Japan \\ Corresponding author, Taira MIYASAKA; E-mail: miyasaka@tky.ndu.ac.jp
}

\begin{abstract}
The polymerization shrinkage values of commercial flowable and conventional composites were measured with a newly developed laser displacement sensor. Compressive strength and filler content were also measured. Compared to conventional composites, the flowable composites required a longer time — not exceeding 4 minutes — to reach a constant polymerization shrinkage rate. In terms of shrinkage ratio, it was less than $1.5 \%$ for conventional composites at 90 minutes, which was lower than that of flowable composites, i.e. more than $2.0 \%$. The compressive strength of conventional composites was higher than that of flowable composites. A highly significant correlation between filler content and polymerization shrinkage at 90 minutes was observed, and polymerization shrinkage tended to decrease as filler content increased. In light of the results obtained in this study, the newly developed displacement meter with a laser displacement sensor proved to be effective for in-depth investigation of the polymerization shrinkage of dental composites.
\end{abstract}

Keywords: Dental composite, Laser displacement meter, Polymerization shrinkage

Received Oct 22, 2008: Accepted Feb 23, 2009

\section{INTRODUCTION}

Dental composite resins, excellent for aesthetic toothcolored restorations, are widely applied in the clinical setting as plastic filling materials ${ }^{11}$. Riding on the current distinct trend towards minimally invasive dentistry, a new type of composite resins called lowflow or flowable composites were developed recently ${ }^{2}$. To increase the fluidity of composite resins, there are various conceivable options: lower the viscosity of the monomeric component ${ }^{3)}$, adjust the filler components ${ }^{4)}$, improve the surface treatment of the filler ${ }^{5}$, or alter the filler content ${ }^{4}$. With respect to the commercial flowable composites that are recently available in the market, their greater flowability was seemed to be attained by lowering the filler content.

In general, variation in the filler content heavily affects thermal expansion ${ }^{6,7)}$, thermal conductivity, polymerization shrinkage ${ }^{7}$, and mechanical strength ${ }^{7}$. Therefore, in order to obtain greater fluidity for the flowable composites, it must be done at the expense of certain properties. To date, no investigations have been undertaken for a thorough, comprehensive comparison on fluidity and polymerization shrinkage between conventional composites and the recently available flowable composites. Further, with regard to measuring the polymerization shrinkage of the highly fluid paste of flowable composite resins, there is an obvious impending need for a new measurement method beyond the traditional ones ${ }^{8-10)}$.

In this study, a highly accurate laser displacement meter was utilized to measure the polymerization shrinkage of highly fluid flowable composites. The aim of this study, therefore, was to evaluate the effectiveness of this new measurement method by measuring the polymerization shrinkage of flowable and conventional composites. In relation to the causes and effects of polymerization shrinkage, the inorganic fillers and mechanical properties were also measured.

\section{MATERIALS AND METHODS}

Table 1 lists the eight commercial composite resins used in this study: four flowable composites and four conventional composites from the same manufacturers.

\section{Measuring polymerization shrinkage}

Polymerization shrinkage was measured with a noncontact laser displacement meter (Fig. 1). The laser displacement meter comprised a diffuse-reflection, high-precision laser sensor head (HL-105B-BK, Sunx, Tokyo, Japan) and controller (HL-C1C, Sunx, Tokyo, Japan), whereby the former consisted of a red laser diode and a linear image sensor as a light receiving element. Measurement center distance of the sensor was $50 \mathrm{~mm}$, the measurable range was $5 \mathrm{~mm}$ to -5 $\mathrm{mm}$, and measurement accuracy was $1 \mu \mathrm{m}$. The digital output of the controller (RS-232C) was fed to a notebook-type personal computer (R50e, IBM, Tokyo, Japan) through the RS-232C to a USB conversion connector (USB-RSAQ3, IO Data, Tokyo, Japan) and measuring software. An intelligent monitor (HLC1AiM, Sunx, Tokyo, Japan) was used to measure dimensional changes arising from polymerization shrinkage.

The measurement conditions were as follows: sampling period was $498 \mu \mathrm{s}$, buffering rate was $\times 8192$, and the number of accumulated data was 1350 . Therefore, the time required for a measurement was the product of the sampling period and buffering rate. 
Table 1 Composite resins used in this study

\begin{tabular}{|c|c|c|c|c|c|c|}
\hline Composite resin & Shade & Type & Code & Manufacturer & Location & Lot no. \\
\hline Clearfil flow FX & A-2 & flowable & CFX & \multirow{2}{*}{ Kuraray Medical } & \multirow{2}{*}{ Tokyo, Japan } & 0004BA \\
\hline Clearfil AP-X & A-2 & conventional & CAX & & & 0820AA \\
\hline Estelite Flow Quick & A-2 & flowable & $\mathrm{EFQ}$ & \multirow{2}{*}{ Tokuyama Dental } & \multirow{2}{*}{ Tokyo, Japan } & J00455 \\
\hline Estelite $\Sigma$ & A-2 & conventional & ESG & & & M2J00664 \\
\hline Unifil Lowflow Plus & A-2 & flowable & ULF & \multirow{2}{*}{$\mathrm{GC}$} & \multirow{2}{*}{ Tokyo, Japan } & 502141 \\
\hline Unifil S & A-2 & conventional & UNS & & & 505131 \\
\hline Beautifil Flow F10 & A-2 & flowable & $\mathrm{BF} 1$ & \multirow{2}{*}{ Shofu } & \multirow{2}{*}{ Kyoto, Japan } & 10502 \\
\hline Litefil II P & A-2 & conventional & LFP & & & 10528 \\
\hline
\end{tabular}

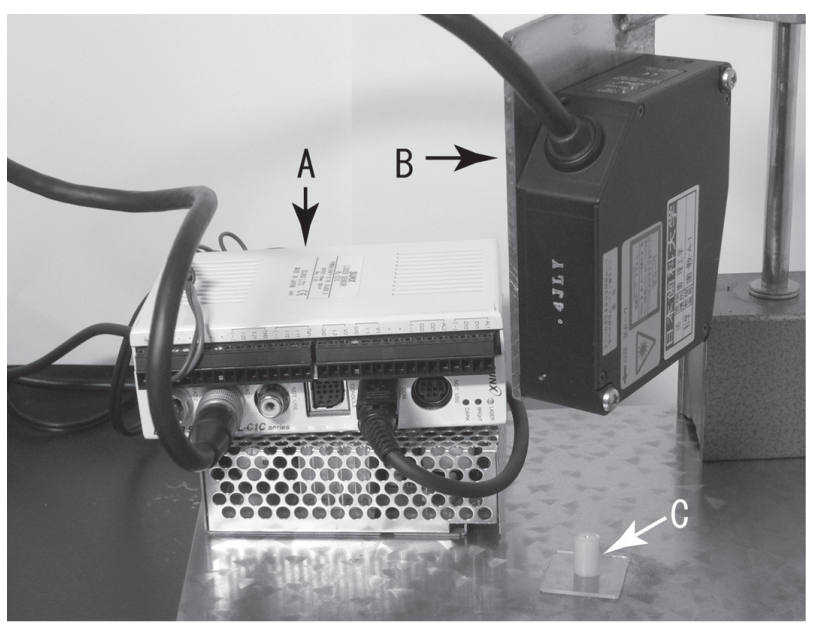

Fig. 1 Laser displacement meter and a composite specimen in a glass tube. A: Controller, B: Laser sensor head, C: Sample

Continuous measurements were made over a duration of more than 90 minutes (91.8 minutes) at 4.08-second $(498 \times 8192 \mu \mathrm{s})$ intervals. After measurement, data (in $\mathrm{mm}$ ) were saved as a CSV file. Further details were as per those given in a previous report ${ }^{11)}$.

With these measuring instruments, dimensional change was measured as follows. On a fixed iron platen, the laser sensor head was fixed to a magnetic stand by a hand-made jig, so that the laser beam projected vertically on the platen. A mirror glass, $50 \times 50 \mathrm{~mm}$, was placed on the platen, and a glass plate ( $1 \mathrm{~mm}$ in thickness, $25 \times 25 \mathrm{~mm}$ in size) was placed on the mirror glass. A glass tube, $6 \mathrm{~mm}$ in inner diameter (8 $\mathrm{mm}$ in outer diameter) and $10 \mathrm{~mm}$ in height and polished vertically on the sidewall, was vertically placed on the glass plate. On the inner surface of the glass tube was applied ethylene glycol with a brush. The position of the laser sensor head was adjusted to a distance of about $50 \mathrm{~mm}$ from the upper end of the glass tube. Then, composite resin was filled to about 1 $\mathrm{mm}$ from the upper end and a piece of aluminum foil $(2 \times 2 \mathrm{~mm})$ was attached to the composite to enhance the reflection efficiency of the laser beam.

The composite resin was cured by a visible light

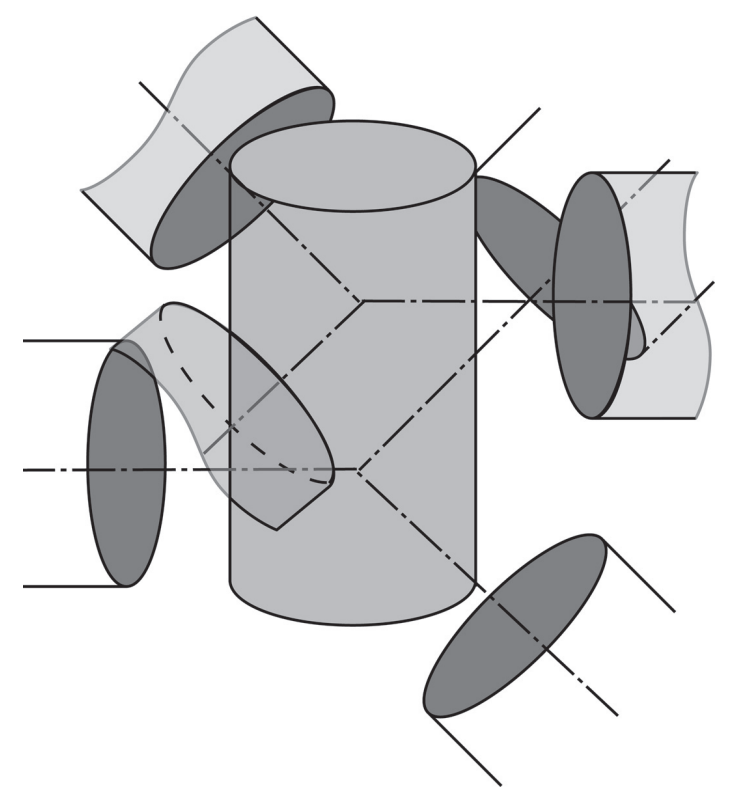

Fig. 2 Schematic diagram of light irradiation.

irradiation equipment (Elipar Highlight, 3M ESPE, USA; intensity: $800 \mathrm{~mW} / \mathrm{cm}^{2}$, tip diameter: $9.3 \mathrm{~mm}$ ) obliquely from the bottom to the top through the sidewall of the glass tube. Light was reflected by the mirror under the glass plate, and hence curing of the composite was expected to start from the bottom. The lower half of the glass tube was irradiated perpendicularly to the long axis from three different directions at 120 degrees for 20 seconds each time. Subsequently, the upper part of the glass tube was also irradiated from three directions. Fig. 2 is a schematic diagram of the light irradiation protocol at different directions. Total irradiation time was 2 minutes.

Dimensional change measurement started from the initiation of irradiation and lasted for a duration of 90 minutes. Subsequently, the specimen was removed from the glass tube and its length measured by a digital caliper (CD-15CP, Mitsutoyo, Tokyo, Japan) to an accuracy of $0.01 \mathrm{~mm}$. The shrinkage ratio thereof was thus calculated. 


\section{Measuring compressive strength}

Cured specimens were placed in spit molds used for preparing dental zinc phosphate cement specimens for compressive strength testing ${ }^{12)}$. The top surfaces of the specimens were wet-ground with silicon carbide papers to become parallel with the bottom surfaces, and the final specimen height was $c a .9 \mathrm{~mm}$. After storage at $37^{\circ} \mathrm{C}$ for 24 hours, compressive strength was measured using a universal testing machine (Autograph DCS10T, Shimadzu, Kyoto, Japan) which operated at a crosshead speed of $1 \mathrm{~mm} / \mathrm{min}$ and at a full scale of 1000 kgf. The compressive strength obtained was the maximum stress on a stress-strain curve.

\section{Measuring filler content}

Inorganic filler content was calculated from the weight of the composite resin before and after combustion. A $10-\mathrm{ml}$ porcelain crucible with a cover was placed in an electric furnace at $500^{\circ} \mathrm{C}$ for 2 hours. After 2 hours of cooling to room temperature in desiccators containing freshly heated and dehydrated silica gel, weighing was carried out in an electronic balance. The heating, cooling, and weighing were repeated until the weight change was within $\pm 0.50 \mathrm{mg}$. Approximately $1 \mathrm{~g}$ of composite resin was added to the crucible of constant mass and measured to an accuracy of $0.01 \mathrm{mg}$, then

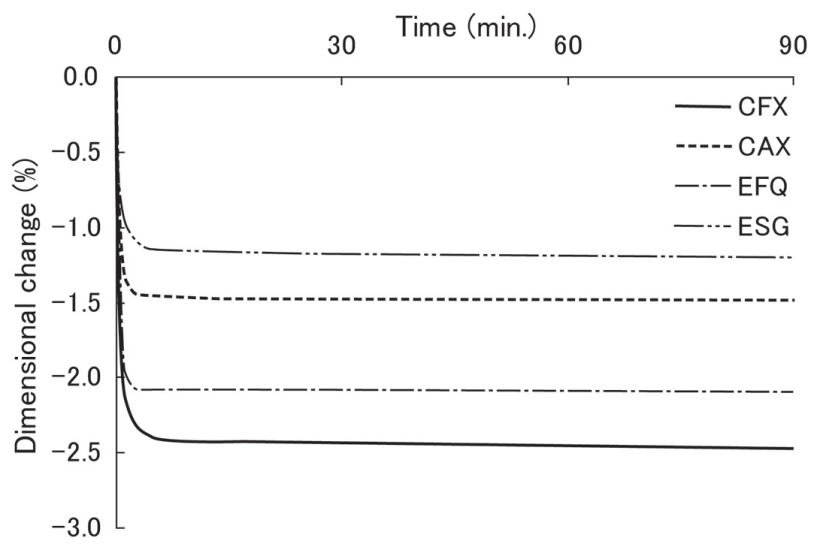

Fig. 3 Curing contractile curves of Clearfil and Estelite composite resins. heated at $500^{\circ} \mathrm{C}$ for 2 hours to burn the organic constituent, cooled, and weighed repeatedly. The inorganic filler content was calculated by subtracting the constant mass of the crucible and ash from the weight of the crucible, and then dividing by the weight of the composite resin.

\section{Statistical analysis}

A two-way layout experimental design, with manufacturer (four companies) and consistency (flowable and conventional) as factors, was adopted. The experiment was performed in a random sequence and there were three iterations. Data were analyzed by two-way ANOVA, and where factors were found to be significantly different, Tukey's test was performed between each level.

\section{RESULTS}

\section{Polymerization shrinkage}

After extracting the displacement data from the CSV file, the polymerization shrinkage of each composite was obtained by dividing the difference between the displacement data at each time point and the starting displacement by the specimen length. In addition, by multiplying the sequential number of measurements by

Table 2 Two-way ANOVA results for asymptotic shrinking time

\begin{tabular}{lrrrrrr}
\hline \multicolumn{1}{c}{ Factor } & s.s. & d.f. & m.s. & \multicolumn{1}{c}{$\mathrm{F}_{0}$} & Significance & Contributing ratio \\
\hline A (Manufacturer) & 1.062183 & 3 & 0.354061 & 1.07 & - & 0.37 \\
B (Consistency) & 7.238017 & 1 & 7.238017 & 21.80 & $* *$ & 38.57 \\
A $\times$ B & 4.292983 & 3 & 1.430994 & 4.31 & $*$ & 18.41 \\
Error & 5.312267 & 16 & 0.332017 & & & 42.65 \\
\hline Total & 17.905450 & 23 & & & $95 \%$ interval of confidence Qij $= \pm 0.705$
\end{tabular}

$* *$ : Highly significant difference $(p<0.01)$ was detected.

*: Significant difference $(p<0.05)$ was detected.

- : No significant difference $(p>0.05)$ was detected.

Similar expressions were used in Tables 3 to 5 .

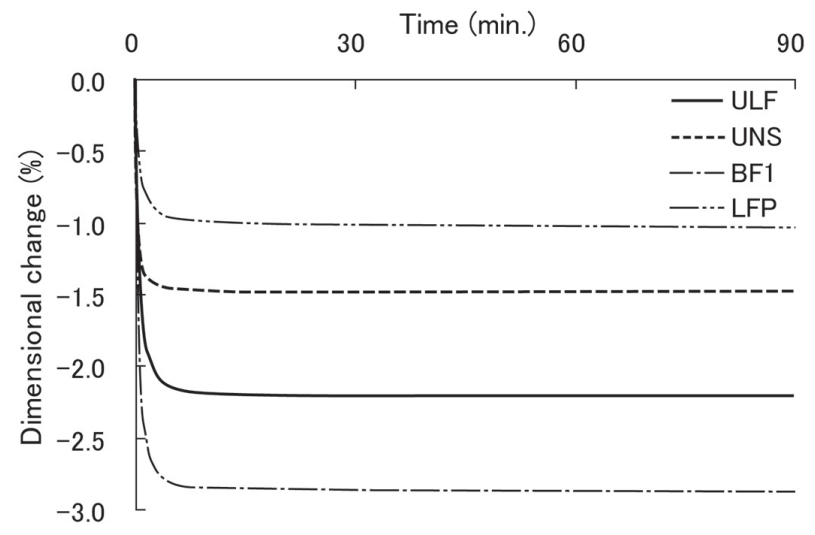

Fig. 4 Curing contractile curves of Unifil, Beautifil, and Litefil composite resins. 
Table 3 Two-way ANOVA results for dimensional change

\begin{tabular}{lcrrrrr}
\hline \multicolumn{1}{c}{ Factor } & s.s. & d.f. & m.s. & \multicolumn{1}{c}{$\mathrm{F}_{0}$} & Significance & Contributing ratio \\
\hline A (Manufacturer) & 0.407810 & 3 & 0.135937 & 7.33 & $* *$ & 3.78 \\
B (Consistency) & 7.492838 & 1 & 7.492838 & 404.13 & $* *$ & 80.15 \\
A B & 1.128503 & 3 & 0.376168 & 20.29 & $* *$ & 11.5 \\
Error & 0.296650 & 16 & 0.018541 & & & 4.57 \\
\hline Total & 9.325800 & 23 & & & $95 \%$ interval of confidence Qij $= \pm 0.167$
\end{tabular}

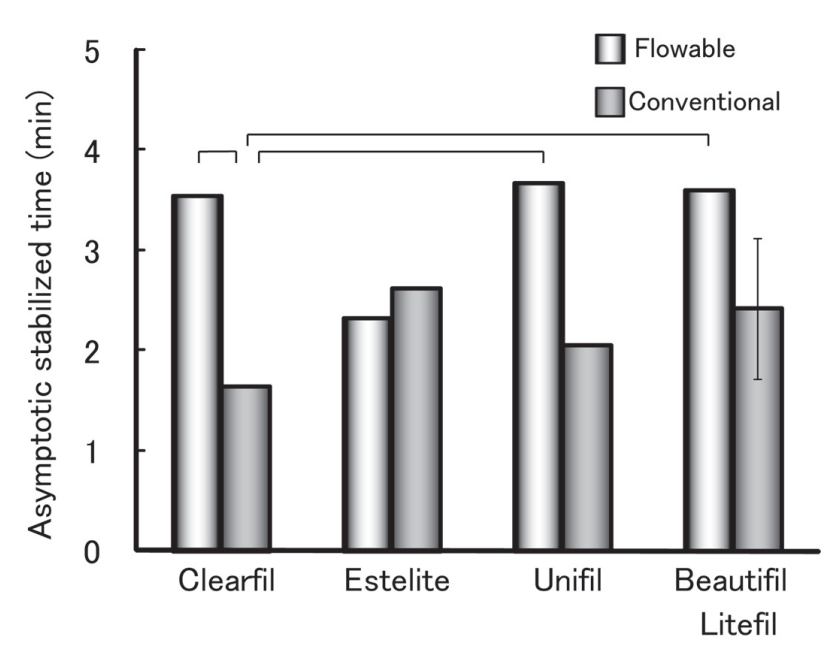

Fig. 5 Asymptotic stabilized times of flowable and conventional composite resins. Horizontal brackets indicate statistically significant differences $(p<0.05)$. Vertical bar represents $95 \%$ confidence interval (similar expressions are used in the following figures).

4.08 seconds, i.e., the measurement interval, a curing contractile curve was drawn. Fig. 3 and 4 show the curing contractile curves obtained by averaging three measurements for each composite.

For all the composites, a smooth curve as a whole was obtained as well as a tendency to reach an asymptotic value within several minutes after the initiation of light irradiation. The average rate of change (\%/second) was calculated from three sequential measurements, and the time taken to reach the asymptotic value was determined when the rate of change became $0.001 \% / \mathrm{sec}$ or less. The time taken to reach the asymptotic value corresponded to the time when polymerization contraction almost ended. Twoway ANOVA results of the time taken to reach the asymptotic value with three iterations are shown in Table 2. The main effect B (consistency) showed a highly significant difference $(p<0.01)$ and the interaction showed a significant difference $(p<0.05)$; therefore, a graphic representation of the interaction $\mathrm{A} \times \mathrm{B}$ is shown in Fig. 5 .

As shown in Fig. 5, the polymerization shrinkage of all composites investigated in this study almost reached an asymptotic value within 4 minutes. Comparing the corresponding composites differing in

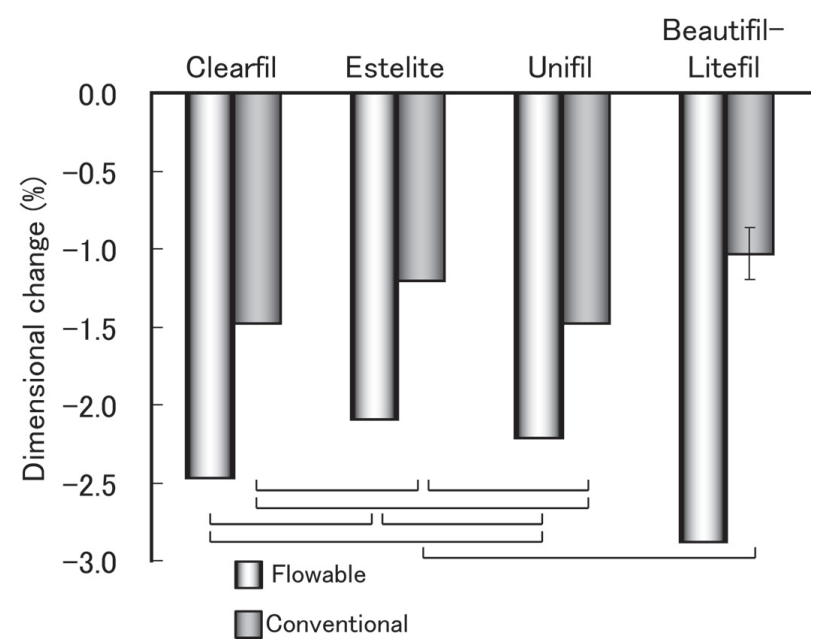

Fig. 6 Dimensional changes of composite resins at 90 minutes from the initiation of light irradiation. Horizontal brackets indicate groups that are not significantly different $(p>0.05)$.

consistency but from the same manufacturer, the time at which polymerization shrinkage almost reached the asymptotic value was longer in the flowable type, except for EFQ and ESG. From 4 minutes to 90 minutes, all shifts in polymerization shrinkage were within $0.06 \%$ and $0.03 \%$ on average - which meant that the shift in polymerization shrinkage after 4 minutes was very small. Concerning the asymptotic values of individual composites, flowable Clearfil exhibited a significantly longer time than its conventional type. When comparison was done among the four manufacturers for each consistency type (i.e., conventional or flowable), there were no significant differences in asymptotic value among the manufacturers. When comparison was done among all the asymptotic values, then that of CAX was found to be significantly shorter than those of ULF and BF1.

Table 3 shows the two-way ANOVA results with three repetitions for the dimensional change ratios at 90 minutes after the initiation of light irradiation. It could be seen that all the main effects exhibited highly significant differences $(p<0.01)$, and likewise for the interaction $(p<0.01)$; therefore, a graphic representation of the interaction $\mathrm{A} \times \mathrm{B}$ is shown in Fig. 6 .

Fig. 6 shows the dimensional change ratios of the 
Table 4 Two-way ANOVA results for compressive strength

\begin{tabular}{lrrrrrr}
\hline \multicolumn{1}{c}{ Factor } & \multicolumn{1}{c}{ s.s. } & d.f. & m.s. & \multicolumn{1}{c}{$\mathrm{F}_{0}$} & Significance & Contributing ratio \\
\hline A (Manufacturer) & 5836.46 & 3 & 1945.49 & 1.64 & - & 2.90 \\
B (Consistency) & 49959.38 & 1 & 49959.38 & 42.11 & $* *$ & 62.13 \\
A B & 3722.46 & 3 & 1240.82 & 1.05 & - & 0.21 \\
Error & 18982.67 & 16 & 1186.42 & & 34.76 \\
\hline Total & 78500.96 & 23 & & & $95 \%$ interval of confidence Qij $= \pm 20.88$
\end{tabular}

Table 5 Two-way ANOVA results for filler content

\begin{tabular}{|c|c|c|c|c|c|c|}
\hline Factor & s.s. & d.f. & m.s. & $\mathrm{F}_{0}$ & Significance & Contributing ratio \\
\hline A (Manufacturer) & 435.09125 & 3 & 145.03042 & 10.58 & $* *$ & 10.12 \\
\hline B (Consistency) & 2694.52042 & 1 & 2694.52042 & 196.58 & $* *$ & 68.84 \\
\hline $\mathrm{A} \times \mathrm{B}$ & 545.41125 & 3 & 181.80375 & 13.26 & $* *$ & 12.95 \\
\hline Error & 219.31333 & 16 & 13.70708 & & & 8.1 \\
\hline Total & & 23 & & & $95 \%$ interva & onfidence $\mathrm{Qij}= \pm 4.5$ \\
\hline
\end{tabular}

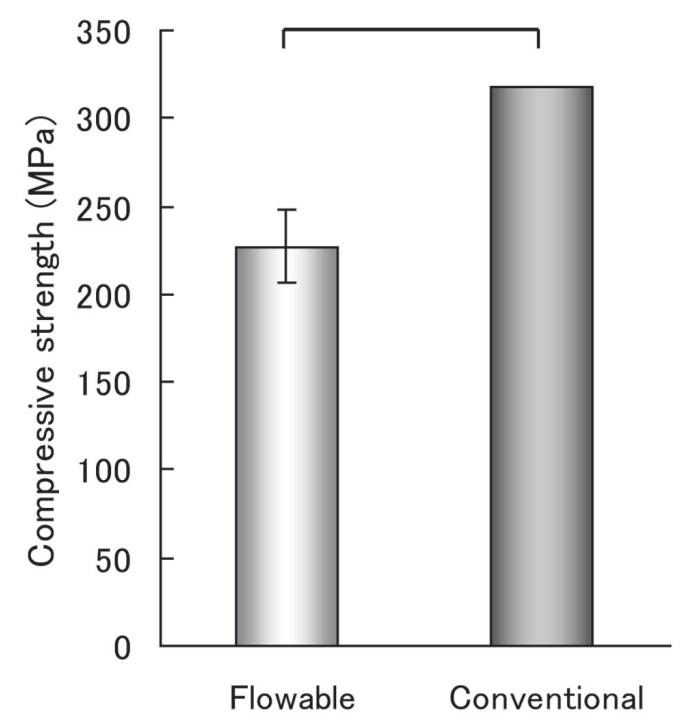

Fig. 7 Compressive strengths of flowable and conventional composite resins. Horizontal bracket indicates statistically significant difference $(p<0.01)$.

composites at 90 minutes after the initiation of light irradiation. It was clear that the dimensional change ratios of the conventional composite resins were smaller than $-1.5 \%$ (ranging between $-1.03 \%$ and $-1.48 \%)$. On the other hand, flowable resins showed relatively larger values that ranged between $-2.09 \%$ and $-2.88 \%$. Further, within the same manufacturer, the dimensional change for the flowable composite was larger than the conventional one. On the overall, BF1 showed the largest dimensional change among the flowable composites, whilst LFP showed the smallest change among the conventional composites.

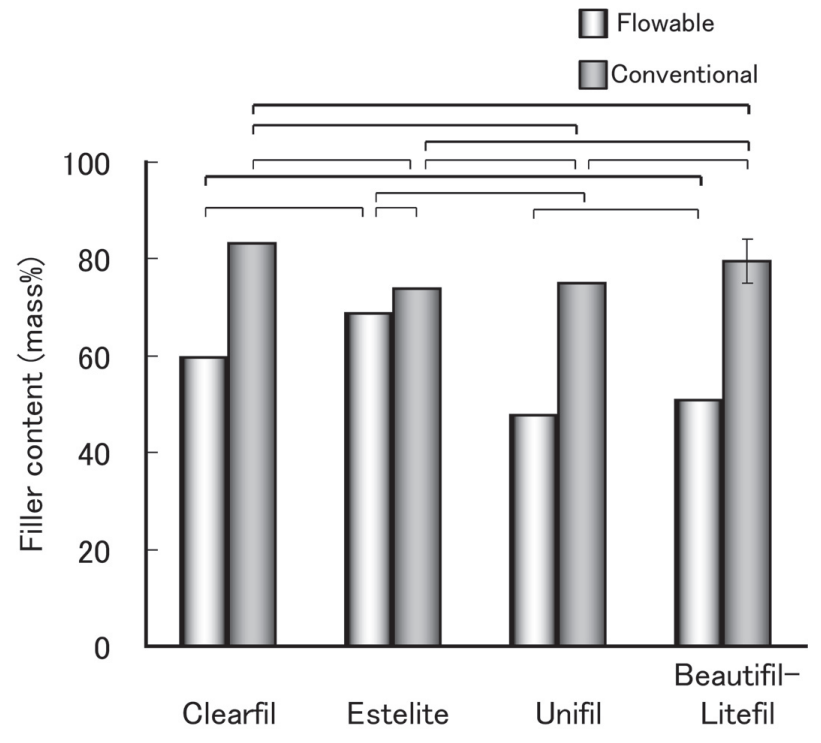

Fig. 8 Filler contents of composite resins. Horizontal brackets indicate groups that are not significantly different $(p>0.05)$.

Compressive strength

Table 4 shows the two-way ANOVA results with three iterations for the compressive strength of the composite resins. A highly significant difference $(p<0.01)$ was found with the main effect B (consistency), and a graphic representation of the result is illustrated in Fig. 7. As shown in Fig. 7, flowable composites exhibited an average compressive strength of $227 \mathrm{MPa}$ whereas the conventional composites exhibited an average of $318 \mathrm{MPa}$.

Filler content

Table 5 shows the two-way ANOVA results with three 
iterations for the inorganic filler content after the burnout of organic components of the composite resins. The main effects exhibited highly significant differences $(p<0.01)$, and likewise for the interaction $(p<0.01)$; therefore, a graphic representation of the interaction $\mathrm{A} \times \mathrm{B}$ is shown in Fig. 8 .

Among the flowable composites, it could be seen from Fig. 8 that ULF exhibited the lowest filler content at $47.8 \%$ whereas EFQ exhibited the highest at $68.8 \%$. Among the conventional composites, the filler content ranged from $73.8 \%$ in ESG to $83.3 \%$ in CAX - and that these values were relatively higher than those of flowable composites.

\section{DISCUSSION}

Recently, flowable composites are widely used in clinical practice instead of conventional composites which are hybrid filled composites with high consistency. In this study, the dimensional change of flowable composites was investigated with a noncontact laser displacement meter.

To facilitate measurement using the non-contact laser displacement meter, the glass tube was used as a measuring mold. Favorably, the glass tube was found to be an effective means of increasing the efficiency of visible light irradiation. Moreover, the ethylene glycol coating on the inner surface of the glass tube reduced the friction between the composite and the sidewall, hence making it possible to obtain a smooth curve for dimensional changes.

With a view to observing the polymerization shrinkage of completely cured composites, the irradiation time of this study was much longer than the normal dose in clinical practice. Thus, smooth asymptotic curves were obtained for both the conventional and flowable composites over a span of 90 minutes. These dimensional curves consisted of values measured every 4 seconds, and it was possible to calculate the average, or arithmetic addition or subtraction from these data. With such data availability, further analyses seemed to be possible.

As an example of such a data analysis, it was possible to calculate numerically the derivative of the first order of the dimensional curves as a dimensional change rate. From these results, the time at which the derivative of the first order reached a certain constant value seemed to nearly coincide with the termination of the rapid polymerization reaction. Fig. 5 shows the results of the termination of the rapid polymerization reaction, whereby the termination times of flowable composites were relatively longer than those of conventional ones - but nonetheless still less than 4 minutes. The derivative of the first order was a nonzero value at such times. Therefore, although polymerization shrinkage was not brought to an absolute completion, it could be said that the apparent polymerization shrinkage terminated within 4 minutes.

On dimensional change, the conventional composites exhibited small negative values less than

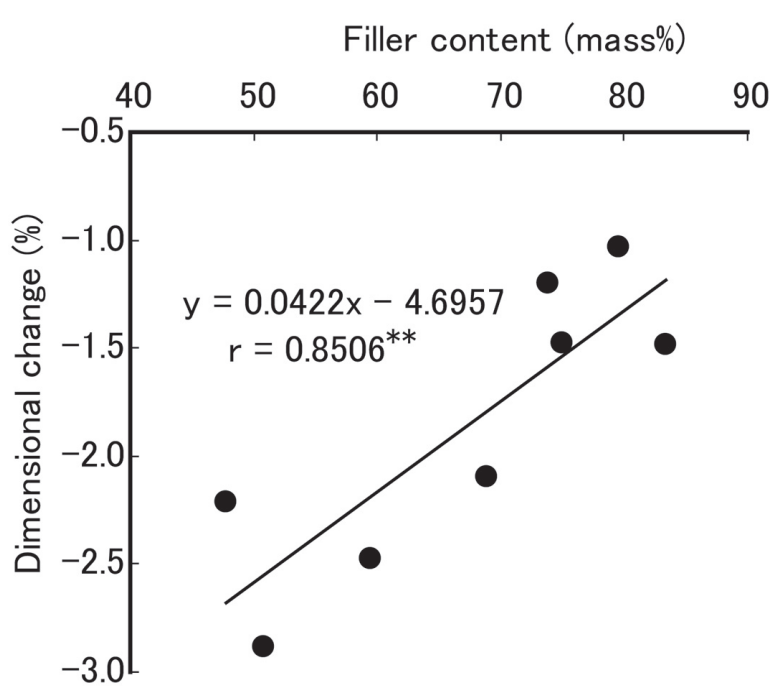

Fig. 9 Correlation between filler content and dimensional change.

$1.5 \%$ at 90 minutes after the initiation of light irradiation, whereas those of flowable ones were relatively larger at more than $2 \%$. In a previous study $^{13)}$, the linear dimensional changes of the same flowable composite resins ranged from $-1.00 \%$ to $-1.24 \%$ - which were much smaller than those obtained in the present study. This disparity could be caused by the shorter irradiation time and measuring time employed in the previous study ${ }^{13)}$. On the other hand, by means of digital video image analysis method $^{14)}$, larger values were obtained: $-0.6 \%$ to $-1.3 \%$ for conventional composites, $-1.2 \%$ to $-2.0 \%$ for flowable composites, and $-2.3 \%$ to $-4.7 \%$ for filled adhesives. Notably, these values ${ }^{14)}$ agreed with the results of the present study.

With a view to accurately assess the effect of filler content on dimensional change, the correlation between the average filler content of each composite resin and the average dimensional change was examined. The results obtained at 90 minutes after initiation of light irradiation are shown in Fig. 9. The equation of the linear regression line and the correlation coefficient are also presented. A highly significant correlation between filler content and dimensional change was found in that the dimensional change tended to decrease as filler content increased. Taking together the filler content results shown in Fig. 8, the large dimensional changes of flowable composite resins could be explained by the highly significant correlation between filler content and dimensional change shown in Fig. 9. In other words, an increase in filler content might help to reduce dimensional changes.

Further on filler content, it should be highlighted that filler weight content might not necessarily correspond to the volume content. Nonetheless, although the inorganic filler used in dental composite resins consists primarily of silica, there were not much 
of a difference between the density of the silica filler and that of chemically different component fillers such as alminosilicate, silica-zirconia, or silica-titania. This assertion was based on results calculated from the volume $\%$ and mass $\%$ provided by the manufacturers. For example, in the case of ESG with a filler content of $82 \mathrm{wt} \%(71 \mathrm{vol} \%)^{15)}$, and with $d_{\mathrm{m}}$ as the density of resin matrix and $d_{\mathrm{f}}$ as the density of the filler, the following equation could be set up:

$$
d_{\mathrm{f}} \times 0.71 /\left(0.29 \times d_{\mathrm{m}}+0.71 \times d_{\mathrm{f}}\right)=0.82
$$

Estimating $d_{\mathrm{m}}$ to be $1.20 \mathrm{~g} / \mathrm{cm}^{3}$, the calculated value of $d_{\mathrm{f}}$ was 2.23. Similarly, in the case of EFQ where the filler content was $71 \mathrm{wt} \%(53 \mathrm{vol} \%)^{16)}$, the calculated value of $d_{\mathrm{f}}$ was 2.60. Since these densities that ranged between 2.20 and 2.67 were similar to the silica filler ${ }^{17)}$, the weight percentage of the filler used in this study would be proportional to the volume percentage. On this ground, the effect of filler contents could be discussed by weight content instead of the volume content.

Although the difference in filler content (wt\%) between ESG and EFQ was relatively small, EFQ showed a large dimensional change when compared to ESG. The reason for this large dimensional change despite a relatively small filler content difference might be caused by the large filler density of $\mathrm{EFQ}$ as compared to the small filler density of ESG.

In general, mechanical strength tended to increase with increase in filler content. In this study, therefore, compressive strength tended to increase with increase in filler content and decrease in dimensional change, although no significant correlations were found. This might be because the data on the compressive strength of composite resins show large variations, and not because of insufficient iterations of the samples. It should be highlighted that the filler contents of several composites obtained in this study coincided with the result of Takamizawa et al. ${ }^{6}$. Therefore, it was hereby suggested that the absence of significant correlation was due to a large variation in data.

From the results of this study, it seemed that the method employed herein could accurately measure the dimensional change behavior of both conventional and flowable composite resins, independently of their fluidity. Moreover, the data obtained by this newly developed method made it possible for more detailed analyses.

\section{CONCLUSIONS}

The polymerization shrinkage values of commercial flowable and conventional composites were measured with a newly developed displacement meter which comprised a laser displacement sensor. In addition, compressive strength and filler content were measured and the following conclusions were obtained.

1. The time taken to reach a constant polymerization shrinkage rate was longer for flowable composites than for the conventional ones, but nonetheless not exceeding 4 minutes.

2. Shrinkage ratio at 90 minutes after irradiation with visible light was less than $1.5 \%$ in the conventional composites, but more than $2.0 \%$ in the flowable ones.

3. The average compressive strength for conventional composites was $318 \mathrm{MPa}$, which was higher than the average value of $227 \mathrm{MPa}$ for the flowable composites.

4. The filler content of conventional composites, at more than $73.8 \%$, was higher than that of flowable ones at less than $60 \%$, except for one flowable composite which exceeded this range.

5. At 90 minutes after initiation of light irradiation, a highly significant correlation was observed between the filler content and polymerization shrinkage, whereby polymerization shrinkage tended to decrease as the filler content increased.

Based on the above results, the newly developed displacement meter that comprised a laser displacement sensor was concluded to be effective for detailed investigation of the polymerization shrinkage of dental composites.

\section{ACKNOWLEDGMENTS}

This study was supported in part by a Grant-in Aid for Scientific Research from the Ministry of Education, Culture, Sports, Science and Technology, Japan.

\section{REFERENCES}

1) Miyazaki M, Rikuta A, Kurokawa H, Takamizawa T. Main stream of composite resin restoration. Nippon Dent Review 2005; 753: 47-60.

2) Kumagai S. Esthetic restoration utilizing flowable resins. Nippon Dent Review 2005; 753: 87-94.

3) Okamura H, Miyasaka T, Hagiwara T. Development of dental composite resin utilizing low-shrinking and lowviscous monomers. Dent Mater J 2006; 25: 437-444.

4) Miyasaka T, Yoshida T. Effect of binary and ternary filler mixtures on the mechanical properties of composite resins. Dent Mater J 2000; 19: 229-244.

5) Miyasaka T. Effect of shape and size of silanated fillers on mechanical properties of experimental photo cure composite resins. Dent Mater J 1996; 15: 98-110.

6) Takamizawa T, Yamaguchi K, Yamamoto A, Nakamura K, Yoshida T, Irokawa A, Miyazaki M, Hinoura K. Filler contents and coefficient of thermal expansion of light-cured resins. Adhes Dent 2005; 23: 143-151.

7) Hirose H, Kawamoto Y, Kojima T, Sakaguchi S, Kimura K, Saitoh M, Yoshihashi K, Matsumura H, Nishiyama M. Density, polymerization shrinkage, filler content and coefficient of thermal expansion of composite resins for crown and bridge. J J Dent Mater 2006; 25: 62-68.

8) Yamamoto A, Miyazaki M, Rikuta A, Kurokawa H, Takamizawa T. Comparison of two methods for measuring the polymerization characteristics of flowable resin composites. Dent Mater 2007: 23: 792-798.

9) Tiba A, Charlton DG, Vandewalle KS, Ragain JC Jr. Comparison of two video-imaging instruments for measuring volumetric shrinkage of dental resin composites. J Dent 
2005; 33: 757-763.

10) Ikejima I, Matsuzawa N, Momoi Y. A newly-designed method for measuring polymerization linear shrinkage of light-activated resin composites. Jpn J Conserv Dent 2003; 46: $273-281$.

11) Miyasaka T, Okamura H. Measurements of setting expansion of dental gypsum and investments using laser displacement sensor. J J Dent Mater 2008; 27: 466-474.

12) Dental zinc phosphate cement, JIS T6602-1993, Japanese Industrial Standards Committee.

13) Uyama S, Irokawa A, Iwasa M, Tonegawa M, Shibuya Y, Tsubota K, Takamizawa T, Miyazaki M. Influence of irradiation time on volumetric shrinkage and flexural properties of flowable resins. Dent Mater J 2007; 26: 892897.

14) Labella R, Lambrechts P, Van Meerbeek B, Vanherle G. Polymerization shrinkage and elasticity of flowable composites and filled adhesives. Dent Mater 1999; 15: 128137.

15) http://www.tokuyama-dental.com/estelite_sigma.htm, Catalog of Estelite $\Sigma$, Tokuyama Dental.

16) http://www.tokuyama-us.com/estelite_flowquick.htm, Catalog of Estelite Flow Quick, Tokuyama Dental.

17) Sławomir MAJ. Optical properties of geomaterials: specific refraction of low-density silica polymorphs. Acta Geophysica Polonica 2004; 52: 77-89. 